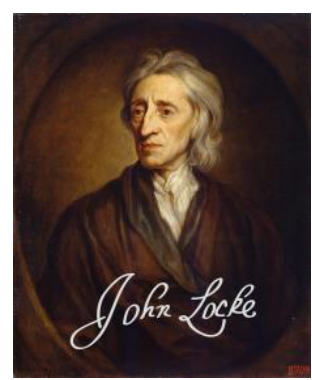

LOCKE STUDIES

Vol. 15

https://doi.org/10.5206/ls.2015.678 | ISSN: 1476-0290

Originally published: 2015

Published online: 19 FEBRUARY 2018

(C) Locke Studies, 2015

\title{
Locke and the Real Problem of Causation
}

\author{
WALTER OTT (UNIVERSITY OF VIRGINIA)
}

Recommended citation:

Ott, Walter. "Locke and the Real Problem of Causation." Locke Studies 15 (2015): 53-77.

https://doi.org/10.5206/ls.2015.678

For more information about this article:

https://ojs.lib.uwo.ca/index.php/locke/article/view/678

Locke Studies is published by The John Locke Society.

This is an open access article published under the terms of the Creative Commons Attribution-

NonCommercial-ShareAlike 4.0 International license, which permits use, distribution and reproduction in any medium, provided the original work is properly cited and shared under the original license. 


\title{
LOCKE AND THE REAL PROBLEM \\ OF CAUSATION
}

\author{
WALTER OTT
}

Any number of problems about causation emerge when one puts Locke into contact with other philosophers such as Hume. But Locke's real problem with causation is internal to his view. It is very simple: Chapter xxvi of Book II of the Essay is entitled ' $O f$ Cause and Effect, and other Relations'.' Yet Locke has just finished explaining that relations are not real. So causation is not real.

The conclusion is intolerable. No commentator I know of denies that Locke takes causation to be a feature of the mindindependent world. ${ }^{2}$ The first premise seems undeniable: while some contemporary authors deny that causation is a relation, Locke cannot be drafted into their ranks. ${ }^{3}$ The second premise, then, might be made to give way: perhaps, despite all the evidence to the contrary, Locke does not really mean it when he says that relations are "not contained in the real existence of Things'. ${ }^{4}$

I will not pursue that possibility, as I am among the majority of writers on the subject who take Locke at his word. ${ }^{5}$ All of us face

${ }^{1}$ References to the Essay are to the edition of Peter H. Nidditch (1975), and in the following form: Book.chapter.section: page number.

2 As Angela Coventry (2003) notes, there is no shortage of commentators who think that Locke anticipates Hume's claim that outer experience provides us with no idea of power. I find Coventry's arguments to the contrary persuasive. But none of her interlocutors would deny that, for Locke, bodies in fact are causes.

${ }^{3}$ See, e.g., Boris Hennig (2011).

${ }^{4}$ Essay, II.xxv.8: 322.

5 Among those who deny the extra-mental reality of relations are Jonathan Bennett (1971, 253-54), myself (2009, 159-69), and Matthew Stuart (2013, 24-32). Rae 
what I am calling the real problem of causation because we agree that, in some important sense, Locke does not count relations among the furniture of the world. Rather than try to read away Locke's anti-realism about relations, I want to see just how far we can go in making sense of such a sparsely populated ontology.

\section{§1. Relations}

For most of the history of philosophy, some version of antirealism about relations has been prominent, if not dominant. (It may still prevail today among those who take up the topic). ${ }^{6}$ This is hardly surprising. For consider how strange the world would look if relations were real. Alongside the array of individual objects and their intrinsic properties, we would have a nearly infinite panoply of $n$-adic tropes. There would be, for example, not just the set of actual human faces and their intrinsic properties, but $\ldots$ has more/fewer pores than $\ldots, \ldots$ is lighter/darker than ..., and so on, and enough of them to connect each face with all others. As Peter Auriol put it in the fourteenth century,

if the face of whatever man is different from the faces of all [other] men, the man's face will be burdened with innumerable realities, because he will have as many real dissimilitudes and differences of form in [his] face as in a subject as there are [other] men.

But it is not just ontological profligacy that bothers the nominalist. Locke claims that 'Cajus, whom I consider to day as a Father, ceases to be so to morrow, only by the death of his Son,

Langton 2000 argues for the reality of relations; see Stuart 2013 and my 2009 for objections to Langton's view.

6 The best recent treatment of the ontology of relations is John Heil's (2012), ch. 7. On Heil's view, as on Locke's (as I read him), there are non-relational truthmakers for relational truths.

7 Quoted in Mark Henninger (1989, 156). William of Ockham (1974, 162 and 174) gives a parallel argument, using relations of distance instead of similarity. 
without any alteration made in himself ${ }^{8}$ And yet if relations were real, there would be a genuine change in Cajus. Locke's contemporary, Robert Boyle, makes exactly the same point when he tells us that ' $[u] n l e s s$ we admit the doctrine I have been proposing, we must admit that a body may have an almost infinite number of new real entities accruing to it without the intervention of any physical change in the body itself ${ }^{9}$. Both the parsimony and change arguments can be traced back at least through the medievals and, in the case of the change argument, to Aristotle himself. ${ }^{10}$

This background explains why Locke feels no need to trumpet his position on relations: he is simply giving us the default position. In an off-hand remark, Locke says that relations are 'not contained in the real existence of Things, but something extraneous, and superinduced'. ${ }^{11}$ I have argued at excruciating length elsewhere that Locke means just what he seems to mean. ${ }^{12}$ I won't repeat those arguments here. And as I've mentioned, although it is far from uncontroversial, the majority of authors who have taken up Locke's view of relations converge on some

${ }^{8}$ Essay, II.xxv.5: 321.

${ }^{9}$ Boyle 1991/1666, 24.

10 Physics $5.2225^{\mathrm{b}} 10-13$, in Aristotle 1984. There are any number of other problems waiting for the realist. Leibniz, for example, holds that it is incoherent to suppose that a single entity can have, as it were, one foot in one substance and one foot in another. See especially the Letter to Des Bosses of 29 May $1716(1989,202)$. And it is easy to generate awkward questions for the realist. Suppose $a$ is to the left of $b$ at t-1 and at t we (almost) instantaneously swap $c$ for $a$. What happened to the trope ... to the left of...? Did it disappear, only to be replaced by a numerically distinct but otherwise indistinguishable trope? Or does it persist, with one flank unsaturated for an instant? In short, what are the persistence conditions for relations? I can't see any way to answer such questions short of brute stipulation, which is usually a sign that we are dealing with something mind-dependent.

11 Essay, II.xxv.8: 322. I say 'off-hand' because the main point Locke is making in the sentence is that one can sometimes grasp the idea of a relation more easily than that of the relata.

12 See my 2009 and (forthcoming.) 
version of anti-realism.

The most stark anti-realist reading is staked out by Matthew Stuart. ${ }^{13}$ On his view, there are no relations, full stop. And there is no way to square Locke's apparent commitment to relations such as powers with this denial. I think we can do a bit better. ${ }^{14}$ I have argued that Locke fits neatly into a tradition we might call 'foundational conceptualism'. ${ }^{15}$ On this view, a claim of the form ' $a R b$ ' can be true even when there is no relation $R$ out there in the world. What counts is whether the monadic features of $a$ and $b$ provide a ground or foundation for the application of the relational concept.

Foundational conceptualism is the best way of taking Locke's words at face value. Locke tells us that ' $[\mathrm{t}]$ he Nature therefore of Relation, consists in the referring, or comparing two things, one to another; from which comparison, one or both comes to be denominated'. ${ }^{16}$ The comparison itself is a mental act. But whether the comparison is apt or not is a question of how things are in the world. Substances and monadic properties are the only truthmakers we need for propositions involving relations. Relations function in much the same way as concepts like the average taxpayer. There are perfectly mind-independent facts that serve as truthmakers for claims about the average taxpayer. And it would be perverse to assume that the average taxpayer itself (himself? herself?) is among them.

The best cases for the foundational conceptualist's strategy are internal relations. By an 'internal relation', I mean a relation that

13 See his 2013, 24 n.

14 I develop and defend this view in my 2009, chs. 16 and 19.

15 One medieval representative of foundational conceptualism is Peter John Olivi (thirteenth century), as Robert Pasnau (2011) reports. Olivi writes, '[i]t does not seem that a relation adds anything real to that on which it is founded, but only makes for (dicit) another real aspect belonging to the same thing' (trans. and quoted in Pasnau 2011, 236).

16 Essay, II.xxv.5: 321. 
obtains, if and when it does, solely in virtue of the monadic properties of the relata. Even those who do not endorse foundational conceptualism full stop are happy to deploy it in such cases. ${ }^{17}$ Assuming that ' $\ldots$ is larger than ...' is an internal relation, there is no call to posit an extra something, beyond the sizes of the relata, to ground 'the table is larger than the soda can'. Similarity relations are also internal; that these two fire hydrants resemble each other in respect of shape does not require anything over and above the shape of the two hydrants.

Whether it is ultimately successful or not, the motivation for foundational conceptualism is simple: just as Locke says, such a view can at once allow us to affirm the truth of at least some propositions about relations while preventing the ontological explosion unrestrained realism threatens. Among the anti-realist readings on offer, it gives us the best chance of saving the appearances.

The initial problem of causation is that Locke's anti-realism about relations threatens to infect causation. We can now replace that formulation with a sharper one: can we understand, if not accept, the claim that the truthmakers for propositions involving causation are nothing but substances and their monadic properties?

A word about the ground rules. First, I will count it as a success if I can show that Locke's foundational conceptualism can account for causal relations. I am not promising here to account for spatial and temporal relations. Those cases are difficult but, at least where space is concerned, I've argued elsewhere that Locke does give us the raw materials for reconstructing his view. ${ }^{18}$ In any case, I will help myself to spatial and temporal relations. As will soon become obvious, there are plenty of problems to deal with even after this concession is

17 For a contemporary use of what amounts to the foundational conceptualist's strategy, deployed with regard to internal relations, see Armstrong 1980, 86-7. The same point is made by Auriol, as reported by Henninger 1987.

18 See esp. my (forthcoming). 
made. I shall also be concerned almost exclusively with bodybody causation.

Second, it is important to be clear on what is to count as a monadic property. I will count as monadic or intrinsic any property of an object $a$ that owes its existence solely to $a$. Some of those properties will in fact characterize $a$ only because of the relations among $a$ 's parts. Texture is a case in point: the texture of a body is a function of how the different parts of its surface are arranged. What Locke needs to be able to do is to show how causation could be understood solely in terms of substances and their monadic properties in the technical sense I have just introduced. He will then need to go on to explain how texture is a function of the intrinsic properties of the parts that make up the body. But again, my focus here is on the prospects for a Lockean account of causation, not of spatial or other relations generally.

\section{\$2. The ideas of cause and effect}

Historians of philosophy have not devoted many pages to Locke's explicit treatment of cause and effect in his Essay. Hume's direct attacks on Locke's derivation of the idea of power have, understandably, focused attention on the early sections of II. xxi. The brief chapter (II.xxvi) has become all but invisible.

From the beginning, those who have discussed the chapter complain of its brevity and superficiality. John Sergeant, for example, writes that Locke 'proceeds not to show us, (which yet he often does in other occasions) in what the nature of Causality consists, which is of the chiefest use in philosophy'. ${ }^{19}$ Even those much more sympathetic to Locke have been hard-pressed to find any merit in the chapter. ${ }^{20}$ The brevity of Locke's account would be a virtue were it substantive and clear. Here again, there is near unanimity among commentators: Locke's discussion is

19 Sergeant 1984/1697, 254. A few years later, Henry Lee complains that Locke has 'omitted' 'the clear stating the Notions of Cause and Effect' $(1702,118)$.

${ }^{20}$ See e.g. R. I. Aaron (1937, 182 f.) and D. J. O’Connor $(1967,94)$. 
'unsatisfying,"21 and 'lacking in depth'. 22

Michael Ayers is quite right to call it 'hardly more than an appendix to the chapter on ideas of relations'. ${ }^{23}$ But causation is a species of relation, so it is fitting that a discussion of it should follow hard on the heels of a treatment of its genus. And the chapter's brevity is also no surprise if, as I shall argue, Locke has something to say about the general nature of causation and little but speculation about the precise form it takes.

Here is Locke's official derivation of our ideas of cause and effect:

IN the notice, that our Senses take of the constant Vicissitude of Things, we cannot but observe, that several particular, both Qualities, and Substances begin to exist; and that they receive this their Existence, from the due Application and Operation of some other Being. From this Observation, we get our Ideas of Cause and Effect. That which produces any simple or complex Idea, we denote by the general Name Cause; and that which is produced, Effect. ${ }^{24}$

The last quoted sentence is puzzling, since it suggests that the only things that merit the name 'effects' are ideas. What follows shows that that cannot be what Locke means. Locke speaks of 'the simple Idea of Heat' as the cause of fluidity in wax. But unless he means to endorse telekinesis, he must be equivocating on 'idea,' as II.viii.8 warns us he will. Sometimes 'idea' means idea; sometimes it means quality.

The second section of II.xxvi, and the last to be concerned with causation, proceeds to sub-divide the general notion of a cause into three categories: creation ex nihilo, the generation or making of a new substance by the re-arrangement of already existing

\footnotetext{
21 Ayers 1991, i, 163.

22 Coventry 2003, 96.

23 Ayers 1991, i, 163.

${ }^{24}$ Essay, II.xxvi.1: 324.
} 
particles, and the alteration of an existing substance such that it takes on a new quality. And that is the whole of Locke's explicit treatment of the ideas of cause and effect. A cause is a producer, whether of a new quality, mode, or substance. Sometimes qualities cause other qualities (as when heat causes fluidity); sometimes the application of one substance to another changes a substance into a new one, as when fire changes wood to ashes.

One question raised, but not answered, by the chapter is this: what is the connection between powers and causes? A quick comparison of II.xxi.1 and II.xxvi.1 reveals that the passages are nearly identical: the ideas of both power and cause arise when the mind perceives change. Nothing in II.xxvi, however, corresponds to II.xxi.4's claim about the introspective origin of our idea of active power. There is no active/passive distinction to be drawn with regard to causes. Perhaps for this reason, Locke's examples in the later chapter are all examples of changes in the extramental world.

The precise relation between power and cause is made clear in Draft B. ${ }^{25}$ Despite our ordinary ways of speaking, powers are relations, not one-place properties. ${ }^{26}$ While Boyle uses the more respectable example of locks and keys, Locke chooses the purgative power of rhubarb as one of his illustrations. On the side of the rhubarb itself, the ability to purge is grounded in its own micro-structure. Whether it counts as a purgative or not depends on whether there are any life forms around with the proper digestive tracts. '[T] he purgeing power in Rhubarb is relative for rhubarb would still be the same were there noe animal in the

25 It is worth noting that, while Locke discusses power and then cause in the Essay, with many unrelated chapters in between, Draft B canvasses the three 'Grand relations' of 'Time place \& causality' (1990, 260), and only then discusses power.

26 Locke says 'Powers are Relations' (II.xxi.19: 243). The powers of gold are 'nothing else, but so many relations' (II.xxiii.37: 317); most of the simple ideas that make up our ideas of substances are powers, "which [are] Relations to other Substances' (II.xxxi.8: 381; see II.xxi.73: 286-87). 
world capable of being purged'. ${ }^{27}$ The state of the rhubarb, whatever it is, that flanks the power relation is an enduring and presumably not very mysterious one. The power comes and goes depending on whether a partner is available to occupy the other side of the relation. Just as foundational conceptualism requires, whether something has a given power turns solely on the monadic properties of the objects involved.

When a substance with the relevant enduring state comes into contact with other suitably arranged substances, the power becomes active. 'The substances where in these powers are when they exert them come under an other relation $\&$ are called causes'. ${ }^{28}$ In the Essay, Locke will make it more clear that qualities as well as substances can be causes. But this seems largely terminological: it's as natural to call rhubarb the cause of the purging as it is to take the cause to be whatever quality about the rhubarb explains the purging. In fact, the Essay is even more generous with the title 'cause': 'whatever is considered by us, to conduce or operate, to the producing any particular simple Idea, or Collection of simple Ideas, whether Substance, or Mode, which did not before exist, hath thereby in our Minds the relation of a Cause, and so is denominated by us'. ${ }^{29}$ So anything relevant to the production of a new quality or substance deserves to be called a 'cause'. Locke shows little interest in the project of isolating causes from background conditions.

How can causation be an internal relation? Let us work through one of Locke's examples. Take a case where heat, or if you prefer the object that is hot, causes wax to become fluid. What is the truthmaker for 'the heat caused the wax to become fluid'? Just this: when heat was applied, the wax lost one quality

${ }^{27}$ Locke 1990, 262.

28

Locke 1990, 262.

29 Essay, II.xxvi.1: 324. The evidence for my point rests on 'conduce' having roughly the same meaning it does today. Pierre Coste supports this assumption by rendering the word as 'contribuant'. 
and gained another. ${ }^{30}$ So far I have ignored the spatial and temporal relations that must be among the truthmakers for causal claims. Locke's account implies that a cause exists before its effect, since the essence of causation is the production of something new, whether substance or quality. And Locke's claim that we get our ideas of cause and effect from witnessing 'the due Application and Operation' of one being on another suggests that cause and effect must be contiguous. Later on, we will deal with action at a distance. But throughout the early drafts and first edition of the Essay, Locke is convinced that bodies cannot act a distance. So we can plausibly read Locke as building spatial contiguity and temporal precedence into his concept of causation, at least in his early stages. Obviously I have done nothing to show how spatial and temporal claims could be made true by monadic properties of bodies. But for now I would remind the reader that I have tabled spatial and temporal relations. ${ }^{31}$ With that caveat, we can say that we have just what the foundational conceptualist requires: a story told using only the intrinsic properties of the causal relata.

Matthew Stuart has pressed an objection that might seem particularly compelling in this context. ${ }^{32}$ If relations are minddependent, then $a \mathrm{R} b$ cannot be true unless there is some mind around to think it. This is bad enough in general but seems

30 It is worth noting just how closely Locke anticipates some contemporary philosophers who endorse a powers view. As Stephen Mumford puts it, if the powers view is right, 'the causal relation would not even be an external one. The existence of the causal relata, the power and its manifestation, is enough alone to ensure that the causal relation exists' $(2009,276)$.

31 Someone might argue that if we cannot arrive at a plausible understanding of spatiotemporal relations on the anti-realist view, we should do whatever is necessary to make Locke into a realist. In my view, this is to allow charity to distort the past. The historian's job cannot be to make every philosopher come out with a clear and consistent position that is also, to us, plausible. Consider what future historians, operating on those principles, would make of the discipline's recent past. Give it two hundred years and someone will argue that David Lewis never really held modal realism.

32 Stuart 2013, 29-30. 
especially implausible in the case of causation: can it really not be the case that heat causes the wax to become fluid unless someone compares these qualities in respect of causation?

Locke has an answer to this objection. Consider his definition of truth:

Truth then seems to me, in the proper import of the Word, to signify nothing but the joining or separating of Signs, as the Things signified by them, do agree or disagree with one another. ${ }^{33}$

There is nothing special about propositions involving causation: no proposition is true unless there is a mind there to think it. Propositions, whether mental or verbal, are mind-dependent. Locke's metaphysics simply has no room for a Platonic heaven where propositions can dwell in splendid isolation.

Nevertheless, we have to keep in mind that the truthmakers for causal propositions are mind-independent. Whether a mind compares any particular heat trope with a neighboring fluidity trope or not, those tropes will be there. Locke's nominalism sweeps aside mind-independent universals and propositions alike. But what really has been lost? The world is as it is regardless of how it is thought of.

There are important limitations on the account of causation we have unearthed. Even if Locke's ideas of cause and effect meet the strictures set out in his prior chapter on relations, they capture only the most superficial elements of causation in the natural world. When we think of things as causes, we 'consider any simple Idea, or Substance, as beginning to exist, by the Operation of some other, without knowing the manner of that Operation'. ${ }^{34}$ Although Locke does not do so, it is helpful to think of his work as unfolding different concepts of causation, each suited to a different layer of reality. What we might call the 'surface' concept of cause and effect is so thin as to be a kind of dummy

\footnotetext{
33 Essay, IV.v.2: 574.

34 Essay, II.xxvi.2: 325.
} 
concept, a stand-in for something only God-like perception could teach us.

The surface concept's limitations also have epistemic consequences. Not having any inkling of the "manner of operation' means that, as Locke puts it in Draft B, '[w]hen we see anything we doe not know that it will either produce such an effect as that thing or that kinde hath producd at an other time'. ${ }^{35}$ Our grounds for making such predictions fall short of knowledge. The only thing that blocks Humean scepticism about induction is the fact that there is a deeper story to be told about causation and the structure of the physical world in which it occurs. Unfortunately, we know almost nothing about that deeper story. ${ }^{36}$

\section{§3. The initial deep concept}

One thing that makes reading Locke challenging is his tendency to shift from the psychological project of describing the origin and contents of ideas to metaphysics and physics. The surface concept of cause and effect is plainly an episode in the psychological project. When it comes to figuring out just whether and how that concept might apply at the deep level, Locke runs into two problems.

First and most obviously, the deep level is deep precisely because it is not available to experience. Whatever is responsible for the macro-level interactions we observe must be taking place at the micro-level. That does not prevent Locke from telling us what kind of thing must be happening at the micro-level. There are metaphysical constraints that can show us the outline of the causal process, if not its details. Second, Locke's early, firm belief that bodies interact only through impulse is challenged by Newton. In the end, Locke changes his mind and revises some passages of the Essay accordingly. The easiest way to approach

35 'nor doe we know that what we see was the effect of such a cause farther than our senses' (1990, 97). Locke makes the same point at Essay, IV.iii.14: 546.

36 This is what leads Ayers to call Locke's concepts of cause and power 'dummy concepts'; see esp. his 1991, i, 163-65. 
this material is to begin with Locke's early view and bracket the whole question of gravitation for the moment.

We know already that Locke's initial deeper concept must conform to his theory of relations. It differs from the surface concept in that it includes an outline of the modus operandi (as Locke refers to it in his drafts) of the causal relation. But there are other differences as well. Above, we saw that Locke takes our concept of cause to apply to anything that is relevant to the production of a new substance or quality. In fact, there is good reason to think that, on Locke's view, there will almost never be a case in which the causal relation is one-one. Locke makes the point explicitly with regard to powers:

[T] he great Parts and Wheels, as I may so say, of this stupendous Structure of the Universe, may, for ought we know, have such a connexion and dependence in their Influences and Operations one upon another, that, perhaps, Things in this our Mansion, would put on quite another face, and cease to be what they are, if some one of the Stars, or great Bodies incomprehensibly remote from us, should cease to be, or move as it does. This is certain, Things, however absolute and entire they seem in themselves, are but Retainers to other parts of Nature. ${ }^{37}$

So in our search for the grounds of the causal relation, we are not confined to the monadic properties of one substance or quality (the cause) and another (the effect). Our idea of cause, which typically allows us to think in such one-to-one terms, is adapted to the surfaces of things, not their depths. But that is not to say that nothing resembling that concept is applicable at the ground floor. Causation will still be a matter of production and it will still be subject to the strictures of any relation, namely, it has to be grounded in the monadic properties of bodies.

We can learn more about the initial deep concept of cause by asking after Locke's vision of science under epistemically ideal conditions. This is speculation, obviously, but it is speculation in which Locke happily indulges:

37 Essay, IV.vi.11: 587. 
[I]f we could discover the Figure, Size, Texture, and Motion of the minute Constituent parts of any two Bodies, we should know without Trial several of their Operations one upon another, as we do now the Properties of a Square, or Triangle...The dissolving of Silver in aqua fortis, and Gold in aqua Regia, and not vice versa, would be, then, perhaps, no more difficult to know, than it is to a Smith to understand, why the turning of one Key will open a Lock, and not the turning of another.

Under these idealized conditions, any air of mystery about the natural world would evaporate. Given knowledge of the minute parts of bodies, we would be able to infer their behavior and macro-level properties. As Locke puts it, to know the properties of gold, 'it would be no more necessary, that Gold should exist, and that we should make Experiments upon it, than it is necessary for the knowing the Properties of a Triangle, that a Triangle should exist in any Matter'. 39

There are many questions to be asked about Locke's view on these issues, and others have asked and answered them well. ${ }^{40}$ Our interest lies in what it can tell us about causation. First, it is hardly an accident that Locke uses the analogy of geometry: an idealized science would be no different in kind from geometry. The perspicuity of geometrical demonstrations is the model and (perhaps unrealizable) goal for natural science.

We can capitalize on Locke's appeal to geometry by taking it as a clue to the kinds of relata that will justify the application of the ideas of cause and effect. And here it is vital that the connections detected by geometers are necessary connections that cannot be reduced to analytic truths. ${ }^{41}$ Locke claims that

38

Essay, IV.iii.25: 556.

39

Essay, IV.vi.11: 585 .

40

See esp. Downing 2007.

41 As Kant points out in the Prolegomena, Locke's treatment of geometry anticipates, in important respects, Kant's own notion of the synthetic a priori. For more on this connection, see Ayers 1991, i, 101. 
[W] can know the Truth, and so may be certain in Propositions, which affirm something of another, which is a necessary consequence of its precise complex Idea, but not contained in it. As that the external Angle of all Triangles, is bigger than either of the opposite internal Angles; which relation of the outward Angle, to either of the opposite internal Angles, making no part of the complex Idea, signified by the name Triangle, this is a real Truth, and conveys with it instructive real Knowledge. ${ }^{42}$

This same kind of non-analytic but necessary truth would be captured by the claims of an ideal natural science. These epistemic points are well known; their metaphysical implications are not. Note how Locke's example above works. The relation captured by the proposition in question is nothing but a comparison. But the things being compared are such as to make the resulting proposition necessarily true. In short, the relations in question are internal relations, the very kind foundational conceptualism handles with ease.

Let us step back and see how Locke's theory of relations fits with his theory of cause and effect. We know that any claim of the form ' $a \mathrm{R} b$ ' has to be true in virtue of monadic properties. Now, as we have seen, a completed Lockean science would reveal that there are many more substances involved in any event than just a single cause and a single effect, $a$ and $b$. But for simplicity's sake, we can take ' $a$ ' and ' $b$ ' as referring to whatever monadic properties of whatever substances are relevant. Locke's epistemic claim is that if you knew everything there is to know about $a$, you would be able to predict $b$. The ontological side of this is that there is nothing more to $a$ 's causing than $b$ than the monadic properties of $a$ and $b$.

These points suggest a second line of argument to my conclusion about Locke's picture of cause and effect. Above, I argued from Locke's theory of relations to the conclusion that there can be nothing more to any given causal transaction beyond the monadic properties of the substances involved. But Locke's

${ }^{42}$ Essay, IV.viii.8: 614. 
idealized picture of a completed science provides a second argument to this same conclusion. For if there were something else in play, knowledge of the monadic properties of all the relevant bodies revealed by microscopic investigation would not allow us to know that silver will dissolve in aqua fortis. To know that, you would have to know the mysterious 'something else.' But Locke believes there would be nothing more to know. And to believe that, he has to believe that causal claims are true solely in virtue of the monadic properties of the relata.

That still leaves the problem of motion, of course. How could $a$ 's moving from place $p$ to place $q$ be a matter of $a$ 's intrinsic properties? It can't be. Although as we'll see Locke at times treats motion as an intrinsic property of a body, I doubt that that is his real view. ${ }^{43}$ Although motion is indefinable, Locke agrees with 'the Atomists' who call motion 'a passage' from one place to another. ${ }^{44}$ So motion is going to be a relation. What, then, are its truthmakers? If we can help ourselves to spatiotemporal relations, then the answer is easy: that $a$ exists in $p$ at $t$ and in $q$ at $\mathrm{t}^{\prime}$ is enough to make it the case that a moves from $\mathrm{p}$ to $\mathrm{q}$ in $\mathrm{t}-\mathrm{t}$ '. And although temporal relations remain, as far as I can tell, deeply problematic for Locke, the account of space he considers in Book IV would make spatial relations properties of objects and not relations at all. ${ }^{45}$

The initial deep concept of causation, then, shares some features with its more superficial cousin. Both are constrained by Locke's rejection of relations. That means that the truthmakers for causal claims must ultimately turn out to be nothing but the

43 Note that Locke thinks that our idea of motion is a simple idea, which seems to bar it from being a relation. Ideas of relations are always complex, including at least two constituent ideas and an act of comparison. Nevertheless, Locke's criteria for simplicity where ideas are concerned are notoriously slippery.

44 Essay, III.iv.9: 423. Locke's only complaint is that the atomists have not given a definition of motion; they have merely used new words for the same idea.

45 Essay, IV.x.18: 628. For discussion, see Bennett and Remnant 1978, Downing 2014, my (forthcoming), and below. 
monadic properties (in the technical sense I specified) of the bodies involved. But this deeper concept is nevertheless only provisional, and that for two reasons. First, the initial deep concept still requires spatial contiguity, a requirement Locke drops after becoming acquainted with Newton's works. Second, the initial concept does not adequately account for impulse. In the next section, I argue that these two issues are intimately related and lead Locke toward yet a third concept of causation.

\section{\$4. Problems for the initial deep concept}

Any account of the modus operandi of bodily causes, even in the barest terms, needs some story about what Locke calls 'impulse': the collision of one body into another. In such cases, the struck body gains as much motion as is lost by the striking body. The only conception we have of such a transaction is 'the passing of Motion out of one Body into another; which, I think, is as obscure and unconceivable' as how minds move bodies. ${ }^{46}$ This is a curious predicament. The only way we can think of bodies as acting is by impulse (a claim Locke never backs down from). But the only way we can conceive impulse is itself 'unconceivable'. It is not immediately obvious why the transfer of motion should be inconceivable. But recall that Locke began that chapter of the Essay by telling us that we are constrained to think of simple qualities as subsisting in some substratum and not flitting about on their own. If some determinate motion were to 'jump ship' into another substance, it would violate this principle. Note, too, that the transfer model requires us to think of motion as a monadic property of the moving body. The two notions stand or fall together.

In my view, the most sensible course is to take both the transfer model of impulse and the monadic treatment of motion as placeholders for whatever the real story about impulse at the micro-level turns out to be. It might be the best Locke can do at the moment, but that is because the concept of impulse reflects

46 Essay, II.xxiii.28: 311; cf. my 2009, 179 f. and Stuart 2013, 102. 
the behavior and qualities of bodies at the macro level. Now, someone might argue that Locke's problem with impulse is a conceptual one. And so it is. But again, our concept is itself acquired through experience. Fuller experience-experience of qualities at the micro-level—would, Locke thinks, supply us with a concept of impulse that does not violate the rest of his metaphysical views.

And there is good, independent reason to believe that for Locke the true qualities of matter at the micro-level are not just tiny versions of the primary qualities we perceive at the macrolevel but include some utterly new ones that we cannot now conceive. Famously, Locke writes to Stillingfleet,

It is true, I say [in the Essay] 'that bodies operate by impulse, and nothing else'. And so I thought when I writ it, and can yet conceive no other way of their operation. But I am since convinced by the judicious Mr. Newton's incomparable book, that it is too bold a presumption to limit God's power, in this point, by my narrow conceptions. The gravitation of matter towards matter, by ways inconceivable to me, is not only a demonstration that God can, if he pleases, put into bodies powers and ways of operation above what can be derived from our idea of body, or can be explained what we know of matter, but also an unquestionable and every where visible instance, that he has done so. ${ }^{47}$

Locke alters II.viii.11, the source of his quotation, which now claims that bodies act by 'impulse, the only way which we can conceive Bodies operate in'. ${ }^{48}$ Locke does not change his mind about our conceptual resources. We are still constrained to think of bodies as acting by impulse and, presumably, of impulse as transfer. What has changed is the relation between what is conceivable and what is possible.

But it is not as if this inconceivable way of operating is totally closed off to us. Just as my reading predicts, Locke's theory of relations constrains the range of possibilities he considers. Note

\footnotetext{
47

Locke, Works (10 vols., London, 1823), iv, 467-68.

48

Essay, II.viii.11: 136.
} 
how Locke puts it: God has put into bodies powers that go beyond anything we can derive from our idea of body. It is not that God has decreed laws of nature that force bodies to behave thus and so. If that were the case, we need not be ignorant of any of the monadic properties of bodies, since the laws would swing free of all such properties. It would be our idea of God, or of God's laws, that would be at fault. Instead, what Locke is now convinced of is that our idea of body is inadequate, since bodies have powers that cannot be read off of the ideas we have of them.

These last points help shed some light on the problem of impulse. What Newton shows Locke is that bodies have properties that are not on his list of primary qualities. All along, Locke thinks there is something mysterious about impulse. So when he reads Newton, he is already convinced of our epistemic limitations when it comes to explaining how bodies operate. The problems of impulse and gravity are both shortcomings of our ideas of body and both reflect the same defect: there are qualities in bodies of which we have no idea. Lacking the relevant experience means lacking the requisite ideas, which means lacking the ability to conceive of what is really happening on the ground floor. Locke might not be a mysterian in philosophy of mind, but he is one in philosophy of body.

There is another way to put my point. We know already that there must be a foundation for the causal relation among all the relevant substances. That foundation will be the monadic properties of those substances. The problem is that we don't know what monadic properties might be lurking down there, although we do know that there are at least some we don't know anything about. If we could experience these hidden properties, we would stand in the same epistemic position to those bodies that the locksmith occupies with regard to his locks and keys.

Let me close this section with a quick recapitulation. We begin with the surface concept of cause and effect. This concept is fine

49 See my 2009, 177 f. and Downing 2007 and 2014. 
as far as it goes. But it includes nothing at all about way in which one body or quality brings about a change in the other. In the absence of a God-like vision into the micro-structural features of bodies, we will never have a full grasp of that modus operandi. But we can make some progress, by asking what kind of thing must be going on at that level. Using the concepts we have formed of macro-level objects, we construct the initial deep concept of causation. According to this notion, bodies act by impulse, fitting together as lock and key. Even if we cannot fully grasp impulse itself, impulse must be involved and provides a degree of intelligibility. The real problem with the initial deep concept is that bodies can act in ways other than impulse. (I see no reason to think that Locke's reading of Newton leads him to deny that bodies act by impulse, only that they act in no other way.)

We finally arrive at a more ecumenical, but correspondingly less substantive, deep concept of causation. All that is left, really, is the structure: whatever causal claims are ultimately true, their truthmakers will be nothing but the monadic properties of the bodies involved. And given gravitation, that might well be all the bodies that there are. We found several ways in which all three concepts differ from each other, but let me point here to a new one. The initial concept required spatial propinquity and temporal precedence. The final concept jettisons both of these: by definition, action at a distance violates propinquity. Just as obviously, if body $a$ affects $b$ by gravitation, there is no reason to require that $a$ precedes $b$ in time.

The ultimate truth about causation cannot be fully grasped with our current, impoverished rank of ideas. Locke thinks that such a grasp would require us to revise our surface idea of causation in at least the ways I've suggested. In a different context, Locke speculates that 'if we would emancipate our selves from vulgar Notions, and raise our Thoughts, as far as they would reach', we might come to understand how God first made matter. ${ }^{50}$ Pierre

${ }^{50}$ Essay, IV.x.18: 628. 
Coste tells us that Locke has in mind Newton's suggestion that bodies are nothing but 'thickenings' of space. Bodies, on this view, are just regions of space that God makes impenetrable. Such a view would overturn the everyday ontology of substances and qualities Locke works with. Achieving a complete understanding of the causal structure of the world, if it were possible, would equally require us to 'emancipate our selves from vulgar Notions'.

\section{§. Conclusion}

To sum up: the real problem of causation is that causation is a relation, and relations have no mind-independent existence. I argued that Locke's view of relations allows for the mindindependent existence of the monadic features of things that make it appropriate to compare them in some ways and not others. This is the point of foundational conceptualism, a nominalist view with which Locke and his reader would have been intimately familiar. Foundational conceptualism works best as an analysis (or dissolution) of internal relations, relations that obtain solely in virtue of the monadic properties of their relata. The first problem of causation, then, boils down to the problem of understanding how causal relations could be internal. I then argued that Locke's ideas of cause and effect meet this requirement. And quite independently of his theory of relations, Locke's vision of a perfected science entails that causal relations are internal. For Locke, the world as it is in itself is fully intelligible, if only we could know it. And that intelligibility requires that there be nothing more to a causal transaction over and above the monadic properties of the things being compared under the relation of cause and effect.

No doubt the influence of Hume has partly been to blame for obscuring this whole issue. Like most writers who come after him, Hume focuses on the idea of power and says next to nothing about Locke's ideas of cause and effect. The real problem, internal to Locke's own view, has become all but invisible. Nevertheless, it is hard to resist the temptation to put Locke in 
dialogue with Hume.

In fact, someone might well argue that my account foists an objectionably Humean view onto Locke. After all, if there is no mind-independent causation, since causation is a relation, then Hume and Locke agree. For the realist's fantasy of Causation with a capital ' $C$,' Hume substitutes constant conjunction plus the determination of the mind to move from a thought of one object to another. ${ }^{51}$ How different is this picture from Locke's, in the end?

In one way, the objection is illuminating. Like Hume, Locke has no place for a mysterious, irreducible 'power' or 'cause' lurking in the nature of things. Whatever the ultimate scientific story turns out to be, Locke is convinced it will conform to the outlines of his view. And that view allows only for substances and their monadic properties.

In another way, the objection misses the force of Locke's foundational conceptualism. For Locke, it is still the case that objects in the world are such as to make their comparison under the concept of cause and effect appropriate. The truthmakers for causal claims are fully mind-independent. And when we recognize the necessity that characterizes geometrical claims, we can see a further difference with Hume. For Locke, the monadic properties of bodies are such that they 'fit,' like lock and key. These properties demand that nature take the course that it does.

Hume rejects mind-independent necessity and with it the kind of synthetic necessity Locke thinks such 'fitting' provides. But this is only one dimension of their debate. For Hume, '[s]olidity, extension, motion; these qualities are all compleat in themselves, and never point out any other event which may result from them'. 52 So far, as we've seen, Locke might agree: we cannot use the macro-level qualities experience affords us to predict without fail what will happen next. Locke disavows Hume's assumption

51 I realize this characterization of Hume is controversial. I waded into the old/new Hume debate in my 2009 so I will not do so again here.

52

Enquiry 7.8, in Hume 2006/1748, 136. 
that these are the only kind of qualities that might 'point out' future events. For Locke, gravity shows that there must be qualities of which we have no direct conception operating at the micro level. Although we cannot detect any but the most trivial of 'necessary connexions' among observable qualities, that there are other qualities that are necessarily connected at the micro level is beyond

doubt.

${ }^{53}$ And that necessary connexion is neither a scholastic vis nor a mental projection. Instead, it is a thoroughly pedestrian internal relation which, in the end, obtains solely in virtue of the monadic properties of the bodies concerned. ${ }^{54}$

University of Virginia

53 For Locke's use of the phrase 'necessary connexion' in this context, see, e.g., IV.iii.10: 544.

54 I would like to thank Tim Stanton as well as an anonymous referee for criticisms and suggestions. I am also grateful to Jennifer Smalligan Marušić for comments on an earlier version. 


\section{REFERENCES}

Aaron, R.I. 1937. John Locke. New York: Oxford University Press.

Adams, Marilyn M. 1987. William Ockham. 2 vols. Notre Dame: University of Notre Dame Press.

Aristotle. 1984. The Complete Works of Aristotle, ed. Jonathan Barnes. 2 vols. Princeton, NJ: Princeton University Press.

Armstrong, D. M. 1980. A Theory of Universals: Volume 2: Universals and Scientific Realism. Cambridge: Cambridge University Press.

Ayers, Michael. 1991. Locke. 2 vols. in 1. London: Routledge.

Bennett, Jonathan. 1971. Locke, Berkeley, Hume: Central Themes. Oxford: Clarendon Press.

Bennett, Jonathan, and Remnant, Peter. 1978. 'How Matter Might at First Be Made'. Canadian Journal of Philosophy Supplementary Volume $4: 1,1-11$.

Boyle, Robert. 1991/1666. 'The Origin of Forms and Qualities according to the Corpuscular Philosophy'. In Selected Philosophical Papers of Robert Boyle, ed. M. A. Stewart. Indianapolis: Hackett.

Coventry, Angela. 2003. 'Locke, Hume, and the Idea of Causal Power'. Locke Studies 3: 93-111.

Downing, Lisa. 2007. 'Locke's Ontology'. In The Cambridge Companion to Locke's Essay Concerning Human Understanding. Cambridge: Cambridge University Press.

Downing, Lisa. 2014. 'Locke's Metaphysics and Newtonian Metaphysics'. In Newton and Empiricism, eds. Zvi Biener and Eric Schliesser. Oxford: Oxford University Press.

Heil, John. 2012. The Universe As We Find It. Oxford: Oxford University Press.

Hennig, Boris. 2011. 'Is Causation a Relation?' In Causation and Modern Philosophy, ed. K. Allen and T. Stoneham. London: Routledge.

Henninger, Mark. 1989. Relations: Medieval Theories 1250-1325. Oxford: Clarendon Press.

Hume, David. 2006/1748. An Enquiry concerning Human Understanding, ed. T.L. Beauchamp. Oxford: Clarendon.

Langton, Rae. 2000. 'Locke's Relations and God's Good Pleasure'. Proceedings of the Aristotelian Society 100: 75-91.

Lee, Henry. 1702. Anti-Scepticism. London: R. Clavel and C. Harper.

Leibniz, G. W. 1989. Philosophical Essays, ed. R. Ariew and D. Garber. Indianapolis: Hackett.

Locke, John. 1700. Essai philosophique concernant l'entendement humain.

Trans. Pierre Coste. Amsterdam. (Based on the 4th edition.) 
Locke, John. 1823. The Works of John Locke. 10 vols. London: Thomas Tegg.

Locke, John. 1975. An Essay concerning Human Understanding, ed. Peter H. Nidditch. Oxford: Clarendon Press.

Locke, John. 1990. Drafts for the Essay Concerning Human Understanding and Other Philosophical Writings. Vol.1, ed. Peter H. Nidditch and G. A. J. Rogers. Oxford: Clarendon Press.

Ockham, William of. 1974/1323. Ockham's Theory of Terms: Part I of the Summa Logicae. Trans. M. Loux. Notre Dame: University of Notre Dame Press.

O’Connor, D. J. 1967. John Locke. New York: Dover.

Ott, Walter. 2009. Causation and Laws of Nature in Early Modern Philosophy. Oxford: Oxford University Press.

Ott, Walter. Forthcoming. 'Archetypes without Patterns: Locke on Relations and Mixed Modes', Archiv für Geschichte der Philosophie.

Pasnau, Robert. 2011. Metaphysical Themes 1274-1671. Oxford: Oxford University Press.

Sergeant, John. 1984/1697. Solid Philosophy Asserted Against the Fancies of the Ideists. New York: Garland.

Stuart, Matthew. 2013. Locke's Metaphysics. Oxford: Oxford University Press. 